\title{
Stereotomy and Architectural Design at Foster + Partners
}

\author{
Fabio Tellia ${ }^{1}$
}

Published online: 15 May 2018

(C) Kim Williams Books, Turin 2018

\begin{abstract}
For centuries, stereotomy has been the instrument for building arches, staircases and complex vaulted systems using stone as load-bearing material. Its constructive principles, codified in the classical treatises of few historical figures as Alonso de Vandelvira and Philibert de L'Orme, have found new applications in contemporary architectures, although the carrier is no longer stone, but pre-cast or fabricated components, and the technologies to materialise the whole process have profoundly changed. To demonstrate the great potential that the stereotomic process retains even in a deeply transformed context, the analogies between the stereotomy principles and some of the projects designed by Foster + Partners are outlined. The challenges faced by the builders of the Gothic cathedrals and the great constructions of the Renaissance remain unchanged.
\end{abstract}

Keywords Stereotomy · Foster + Partners · Architectural design · Standardization · Geometry · Vaulted structures

\section{Introduction}

Stereotomy is generally defined as the art of cutting stones into shapes for the construction of vaulted structures. In the last few decades, this art has been revived from the original treatises dedicated to this subject that date back to the sixteenth century and is now being reconsidered as an art which was possibly fundamental to the construction culture of many countries over several centuries. Pérouse de Montclos (1982) identified the concept of national stereotomy to delineate the specific characters of stereotomic construction linked to a certain territory. This re-

Fabio Tellia

fabiotellia@hotmail.com

1 Universidad Politécnica de Madrid, Madrid, Spain 
evaluation of stereotomy has been accompanied by a growing interest in design and constructive experimentation which apply the principles of this art to contemporary artefacts made of stone. Fallacara (2012) has described the most important publications and research centres that have allowed to define the discipline in its second renaissance, that is from the first isolated studies that have originated after the second World War to the contemporary historic and constructive investigations, thus reconstructing a geographic and cultural map that makes up the current state of the art.

This is, however, still a niche area in the wider architectural production of today. In part, this is due to the complexity of the stereotomic design which uses stone as a load-bearing material, as well as to the other challenges it presents, such as the technological problems intrinsic to its design, the structural dimensioning, and the expertise required for the production of the required voussoirs. There is also a scarcity of specific expertise in this field and building codes related to structural stone and environmental performance can act as restrictions and obstacles which are difficult to navigate.

Nevertheless, we can observe how some of the constructive principles characterizing the stereotomic design, once unconstrained from using stone as a load-bearing material, have flourished. These stereotomic principles, which have never ceased to exist, have been applied in many recent architectures with a strong geometrical and technological characterization, perhaps without the architects involved even knowing about their ancient origins and only "re-discovering" such principles during the design process itself.

It does not surprise that constructive principles originated in the Middle Ages persisted until today. For example, the construction of Gothic architecture lasted several centuries, developing in parallel to the other styles during the Renaissance, Baroque and Neoclassicism, until connecting with the romantic Gothic of the nineteenth and early twentieth century (Tellia and Palacios 2015).

The design and construction of complex stone vaulted structures of the past occurred thanks to the master masons' knowledge of geometry, which was required to define the form and volume of the vault and to create the templates passed to the stone masons for shaping the voussoires. The construction of the vaults was optimized in some cases thanks to the advantages given by using arches of equal radius, in others it was achieved conforming the intrados of the vault with surfaces which are easier to draw and to subdivide in patterns as the cone, the sphere or the torus. The ideation of repeatable elements and voussoires allowed to reduce the number of different templates and to simplify the production, storage and collocation in place of each stone block, easing the organization of the construction site.

The principles characterizing the classical stereotomy, once abstracted from their connection with the historical building, can be recognized into the design process of today's most geometrically-focused architectural production. For example, within this ambit, we frequently observe the intent to subdivide and rationalize a complex surface in buildable components, taking advantage of the geometric properties of distinct volumes or shapes. In similar fashion, we observe a precise approach in algorithmic and parametric modelling based on strong geometric foundations to define and transmit the information of a complex shape via a repeatable procedure, which eventually leads to a standardized fabrication of building components. 
Thanks to the development of new technologies and the use of innovative materials, some of the principles of stereotomy have evolved in a way that reduces the number of constraints previously associated with this art, as demonstrated in the recent works of Fallacara, Rippmann and Block (Fallacara 2013; Fallacara and Barberio 2016; Rippmann and Block 2013). The physicals properties of the stone could be enhanced thanks to the synergy of man-made materials bounded to the stone and the difficulties related to representing, producing and building complex surfaces in stone have been overcome with parametric modelling and the use of robotic technologies.

We can identify a facet of the use of the classic stereotomic principles in a variety of works of this millennium from Foster + Partners and, through them, capture one of the directions this discipline appears to take. This article will present an analogy between the classic stereotomic principles described in historical treatises and manifest in many old buildings, and their application in some of the firm's projects. This will show that, even without the exclusive use of structural stone as a construction material whose role is to resist the compression forces of the building, these principles have characterized certain design approaches in contemporary architecture.

The observations brought together in this article, and the analogy with the classical stereotomic principles drawn here, are a personal view rather than a corporate one expressed by any legal entity. The aim of this article is simply to promote a discussion and highlight the cultural foundations of a specific design culture. This article, by considering stereotomic principles, will take a different, and perhaps unusual, approach to viewing certain architectural features.

\section{Stereotomic Principles}

Several definitions of stereotomy have been proposed by authors of the past centuries and by present-day researchers. The analysis proposed in this article requires to identify a framework of principles useful to describe both historical stereotomy and today's approach in stereotomic design.

It could be said that the production process of a stereotomic architecture needs to solve three necessary operations:

1. Voussoir design: an aesthetic intent to organize the stone joints in a way that fulfils structural-geometrical requirements.

2. Template production: an ability to describe geometrically, through projective techniques, any point of a block to produce the required templates (at 1:1 scale) with a coherent and repeatable set of rules.

3. Voussoir production: a stone-cutting protocol aiming at the efficient and standardized creation of any voussoir, even with curved and non-orthogonal faces.

The codification of stereotomy occurred during the Renaissance thanks to the first treatises dedicated to the subject (Palacios 2003). These were initially compiled exclusively in Spain and France. Although they were not the first to be written on 
the subject, the earliest and most widely known treatises from these countries for their completeness of content and diffusion are the works of Alonso de Vandelvira (1578) and Philibert de L'Orme (1567). This codification collected and developed the teachings and constructive principles originating during the Middle Ages in the fervid building sites of the Gothic cathedrals. It proved useful to the stonemasons when constructing arches, stairs and complex vaulted systems, all executed in stone. The cryptic drawings of the stereotomic treatises or notebooks are often accompanied by an explanatory text, which contains information about the design of the architectural element that helpfully suggests its static principle, the geometric projections required to define all the templates necessary for producing the voussoirs and the required stone-cutting instructions.

These drawings, some of which are almost incomprehensible to the uninitiated (Fig. 1), defined a set of geometric relationships necessary for the correct

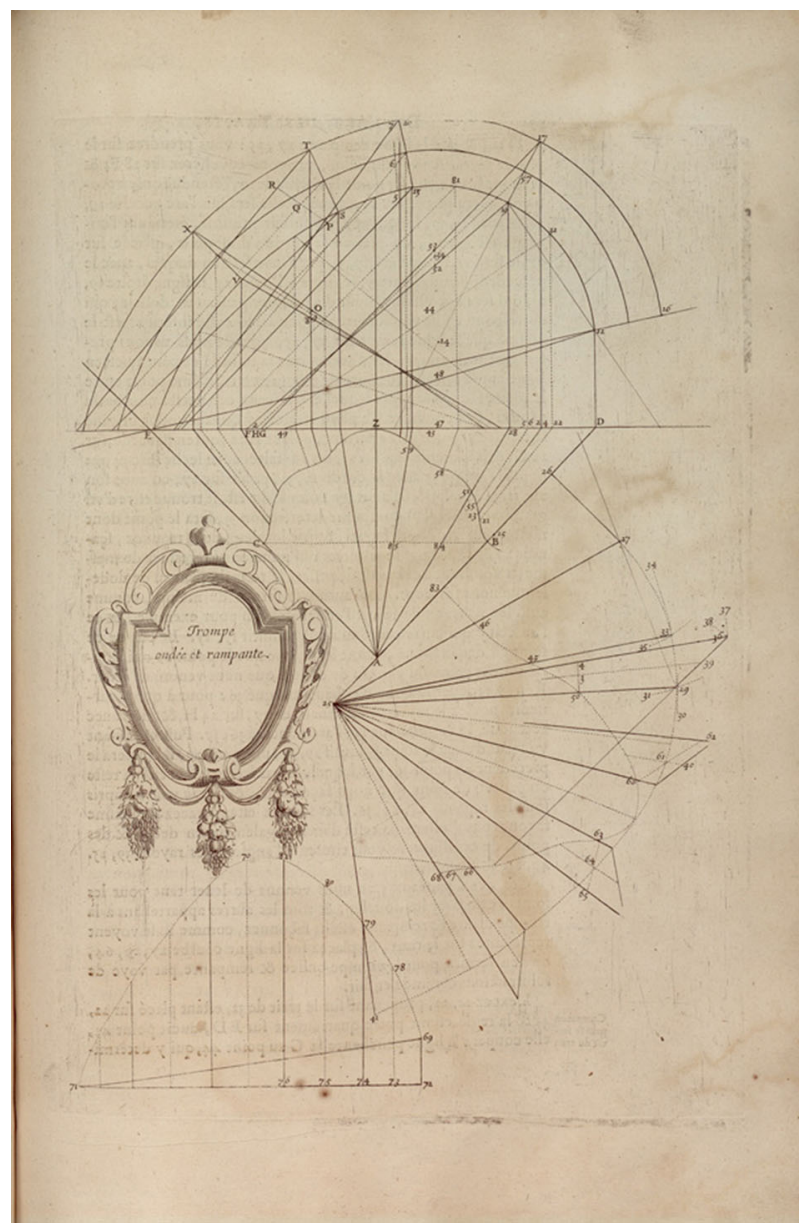

Fig. 1 Trompe ondée et rampante in the treatise of Françoise Derand, 1643 
determination of the components of the vaulted system. They were in effect algorithms (Trevisan 2000) defining a system of relationships between horizontal and vertical sections, which, through a procedure of projection and rotation of points, produced the templates' outline of the elevations and the joint faces of the stone voussoirs.

Some of the surviving Gothic manuscripts contain instructions on how to draw ribbed vaults starting from the planar projection of the ribs by using arches of equal radius, providing one of the first documented instructions on optimization. In Gothic architecture, all elements that could be subdivided eventually divides, driven by the desire to reach increasing complexity (Frankl 1963). Therefore, for the Gothic builder, one of the foremost requirements while ideating the complex geometries of the ribs of the vaulted system was to use voussoirs with the less diverse number of radius of curvature to simplify the construction (Palacios 2009). In many cases, the radiuses used were as little as one only, without ever simplifying or reducing the number of ribs in the web. After fixing the position of the keystones in space (both in plan and elevation), each portion of the arch spanning between the keystones is inclined and rotated over the horizontal plane to reach the correct relative height of the adjacent keystone. The discontinuity of the rib is then absorbed and hidden by the keystones, resulting in a homogeneous network.

As has been observed, Gothic construction is characterized by a tendency towards seeking standardization and simplification that aims to build a complex vault with the least possible number of different arches. By standardizing the voussoirs and absorbing the different inclinations of the ribs in the keystones, all that is required is to cut the receiving arms of the keystones placed in the crossing between ribs at the adequate angle in order to accommodate the incoming or departing rib for each circumstance (Fig. 2).

The systematization of the curvatures of the ribs has clear benefits. A direct benefit is that the execution of the voussoirs is simplified: all the pieces are equal and their production could be streamlined since they do not require different templates. Indirectly, the most significant advantages relate to the organization of the work site: on the one hand, systematization reduces the necessities of numbering and classifying pieces for storage on the construction site and minimizes the errors that can occur when placing the voussoirs in the right position during the construction of the arch; on the other hand, it also makes the transmission of orders from the masters to the stonemasons easier, given that the masters needed to review a reduced number of special pieces. Only the keystones, which are the most complex components of a rib vault, were carefully designed and cut by the more experienced stonemasons.

The geometrical and standardization principles on which Gothic architecture was based, varied from one major developing centre to another-France, Spain, England and the Germanic area. These variations produced different characterizing expressions: in Germany, for example, the Prinzipalbogen was the geometric system that helped define the height of the keystones from the base of the vault according to their position in the plan, working in a fashion which is strikingly similar to a modern parametric tool. In short, the rules of this system required, as an input, the selection of a path in the planar projection of the ribs, starting from the 


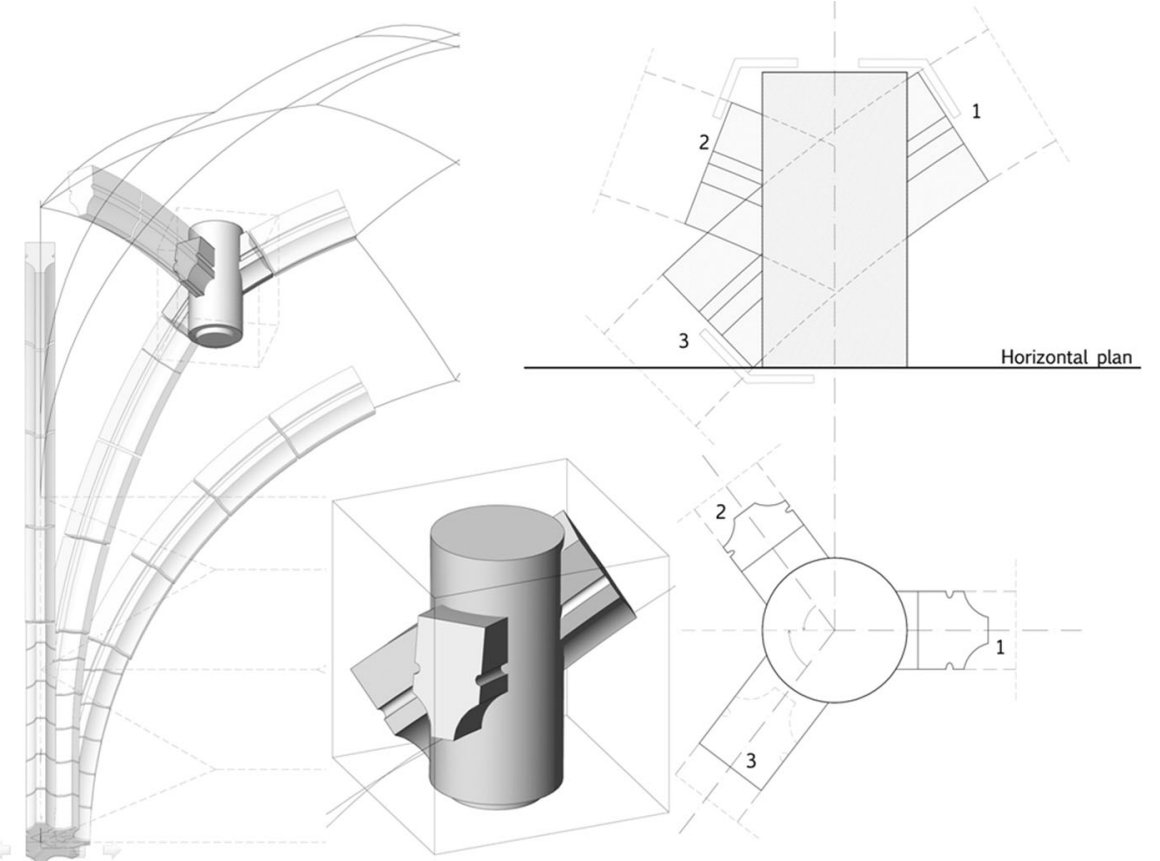

Fig. 2 Keystone at the intersection of three ribs, with the arms cut at different angles to accommodate the incoming or departing rib. Drawing of the author

corner position of one of the columns until it reached the highest point of the vault, eventually passing through the position of the keystones (Fig. 3). The relative lengths of each stretch were used to determine the height of the nodes at which three or more liernes had to meet and, consequently, resulted in fixing the position of the
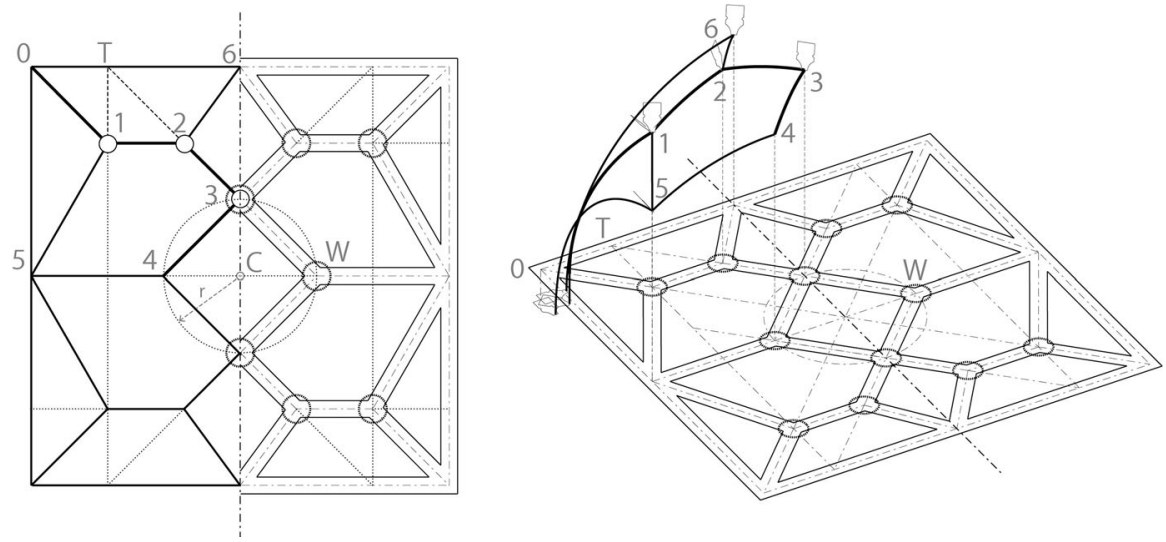

Fig. 3 The position of the keystones in plan and in space as defined by the Prinzipalbogen. Drawing of the author 
keystones. However, this was not a rigid system: by selecting a different path to reach the centre of the vault among the possibilities offered by the more intricate rib designs, the position of the keystones could have been very different, resulting in vaults of different volumetry. Within this set of rules, the personal interpretation of the master builder was fundamental to a successful construction. In each design iteration, the master builder had to decide which parameter had to be prioritized in order to achieve its design intent. If the height of the ridge had to be dominant, the position of the springing of the arches from the supporting columns, to meet two lierne arches at the same or different altitude, would be varied. By varying the parameters, the master builder could achieve a more spherical dome or, alternatively, a more pointed one.

The art of stereotomy flourished thanks to its capacity to define the position of each point of the three-dimensional surface in stone and give its followers the tools to produce it. During the Renaissance, the architect/master mason started to look also for regular surfaces as the geometrical base from which to construct the vaulted structure. The purpose of defining regular surfaces, apart from conforming with the stylistic language of the time, was to make available to architects a geometric support that could be subdivided using original and complicated patterns and developed into the horizontal plane with relative ease in order to produce the templates with which to cut the necessary stone voussoirs. It is notable that this newly developed projective system allowed even double-curved surfaces to be described on paper and developed on the plane with appropriate approximation (Fallacara 2006).

The disposition of the voussoir joints in these structures was inherently linked to the overall shape of the vault. This not only guaranteed the statics of the structure, but it also optimized the construction and achieved the desired aesthetic and complexity.

\section{Analogies}

These features of the stereotomic process are easily readable in several architectures designed by Foster + Partners, although they no longer stick to the pure application of stone as the load-bearing material.

While stereotomy was related exclusively to stone during its foremost development, if we exclude the inventions in carpentry depicted by Philibert De L'Orme (1567), later treatises on the subject have expanded its definition to include timber if the construction principles followed the same thinking, as we can find in the treatises of Leroy (1877) or Rovira i Rabassa (1897, 1900a, b) (Fig. 4). Now, since environmental and ecological components are fundamental part of the equation, the art of construction is doing more intensive use of renewable materials. Wood can be used as component in diagrids but also in machine-cut shapes, as curved arches and structural diaphragms.

The Foster + Partners' architectural project to build the canopy of the Crossrail Place (2015) in Canary Wharf, for example, could be said to share some of the challenges faced by the master builder of a wagon vault in a Gothic cathedral 


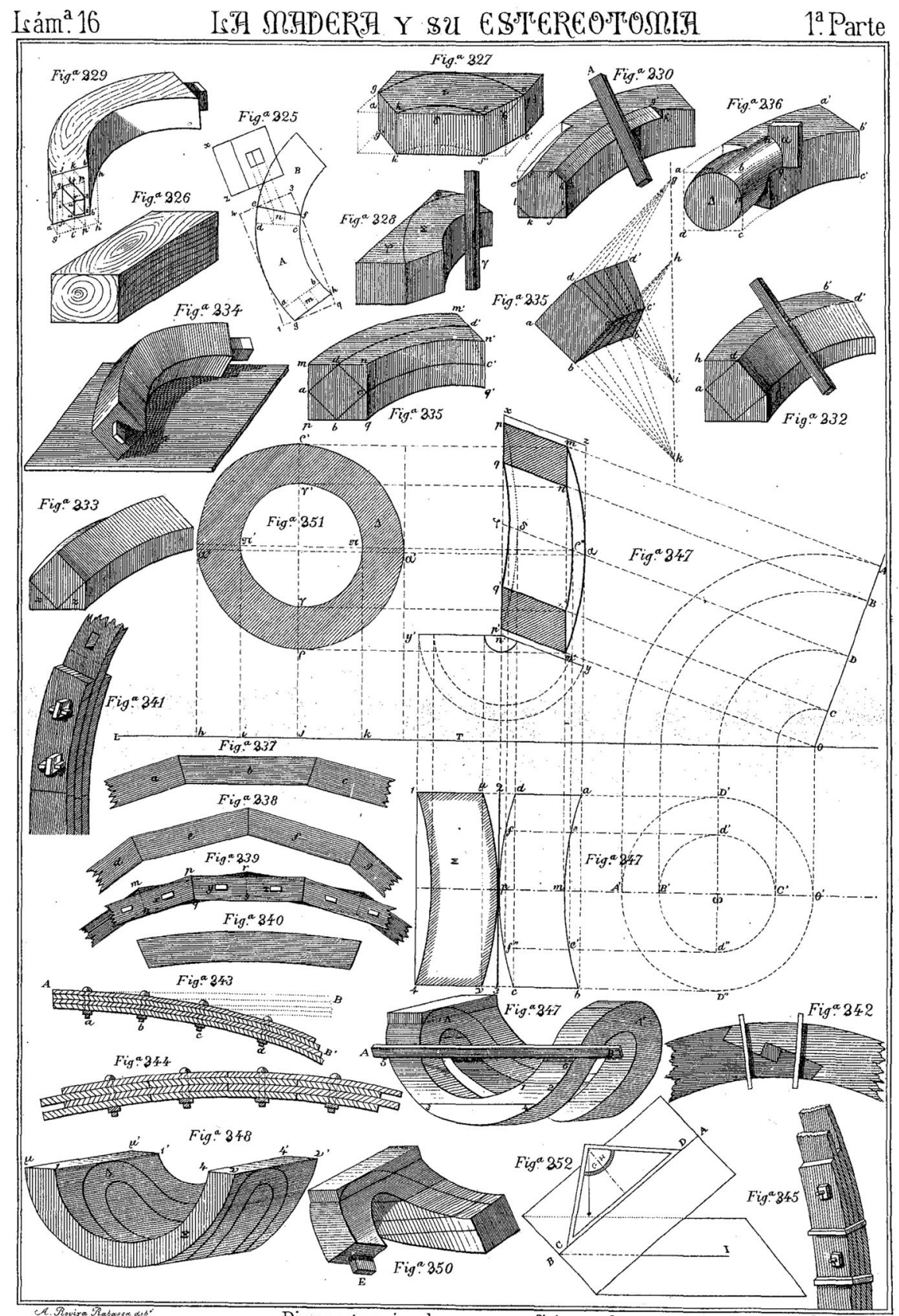

Piezas terminadas en superficies curbas

Fig. 4 Wood stereotomy in Rovira i Rabassa's La madera y su estereotomia 


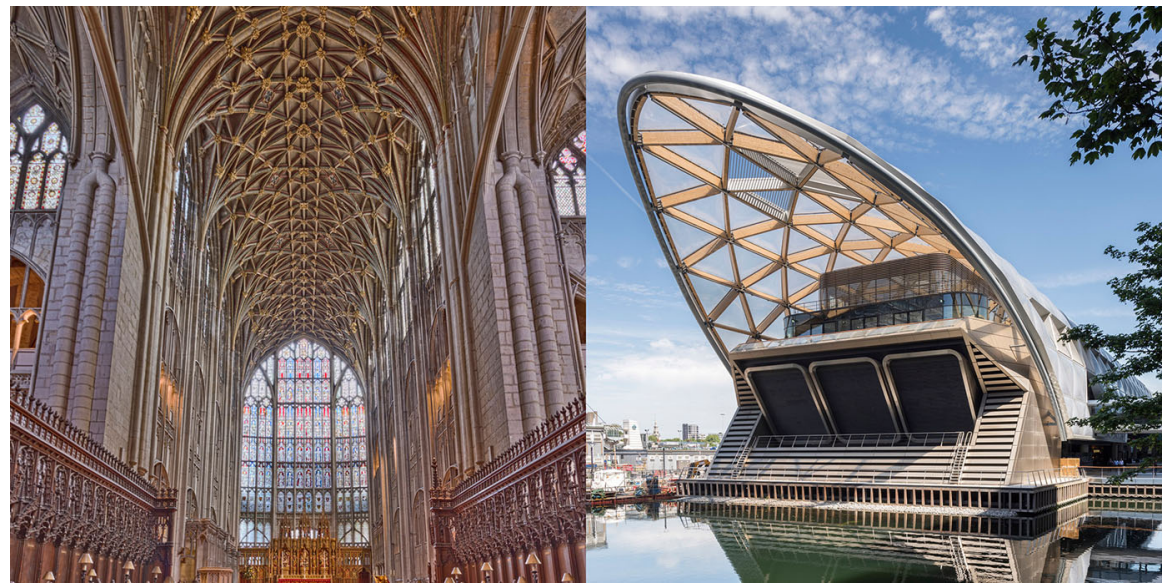

Fig. 5 The Crossrail roof and the vaulted ceiling of the Choir in Gloucester Cathedral

(Fig. 5) in its attempt to organize the constructive process using ribs of the same curvature and differently shaped keystones to absorb the discontinuities among the ribs of the vault. The grid-like canopy enclosing the Crossrail station is a $300-\mathrm{m}$ long timber lattice roof which wraps around the building. The system is composed of more than 1400 straight timber beams connected to steel nodes (Fig. 6); despite the smooth curve of the enclosure, there are only four curved timber beams in the entire structure. To seamlessly connect the straight beams, which rotate successively along the diagonals, the design team developed an innovative system of steel nodes which resolves the twist (Fig. 7). As explained by Rabagliati (2017), the geometry of the roof has been obtained by mediating different constructive constraints and optimizations, resulting in a diagrid which accelerates slightly towards the extremities of the building. The geometrical complexities produced have been moved into the receiving arms of the steel nodes connecting the timber beams, resulting in a simpler production for the other components of the roof. It is possible to see how this procedure could bear a resemblance to the construction process of the gothic rib vaults previously presented.

Some of the firm's earlier projects of shells and large span roofs were heavily based on Euclidean geometry to rationalize the design and make the construction easier with the available building technology. The firm developed a protocol

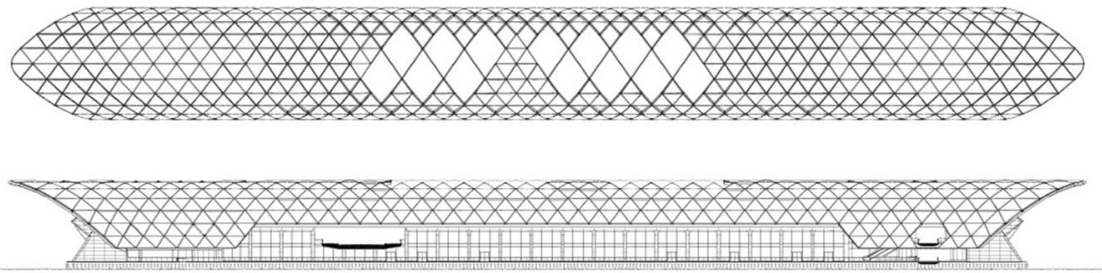

Fig. 6 Plan and elevation of the Crossrail's roof. Courtesy of Foster + Partners 


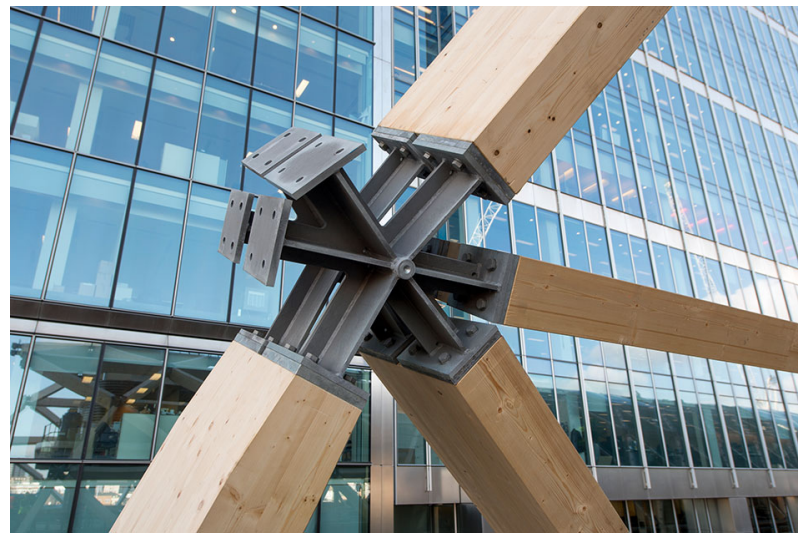

Fig. 7 Steel nodes in the Crossrail roof. Courtesy of Nigel Young/Foster + Partners

(Geometry Method Statement) aiming to communicating the design intent to the consultants and the contractor so the complex geometry could be described using the simplest possible series of steps (Peters 2008). Nodes, lines and control points were defined to locate in space a definite element, exactly as a tracing could have done. Though we cannot demonstrate the direct connection between the sixteenth century stereotomy, the cultural heritage left in the constructive culture is visible.

We can identify the same geometric principles of stereotomy in the definition of the intrados surface and its subdivision in voussoirs in historic stone vaults.

The classical problem of the subdivision of the surface of the sphere in tiles, which also occupied several pages of the stereotomy treatises (Fig. 8), permeates the panalization of the glass dome of the Reichstag (built in 1999) (Fig. 9), which is a half sphere subdivided into parallels. The geometric procedure used to produce the templates is the conic projection, which involves approximating the surface of the sphere into several portions of conical surfaces, each corresponding to a different spherical segment contained by two parallels (Fig. 10).

In the Renaissance, the conic projection was the basis for producing the templates of the squinch vaults (Fig. 11). The same geometric principle has also been used to post-rationalize the construction of the glass surfaces of the London City Hall as stacked sheared cones and to produce the required flat-patterned drawings of the glass curtain wall (Fig. 12).

Another effective approach to define optimized shells lies in the use of translation surfaces, generated by sliding a planar curve along another, while keeping the orientation of the curve constant. This method of regularization was used during the Renaissance in relation to the grid-crossing vault (the bovedas por cruceros of Vandelvira), conceived to produce vaulted surfaces covered by flat stone panels placed between the perpendicular structural ribs (cruceros) of the vault (Figs. 13, 14). The resulting vault may seem spherical, but it is incomparably easier to build, since all its arches are equal and the stone panels placed between the crossing arches are flat quadrilateral blocks. In this specific case, the more complex task is the 


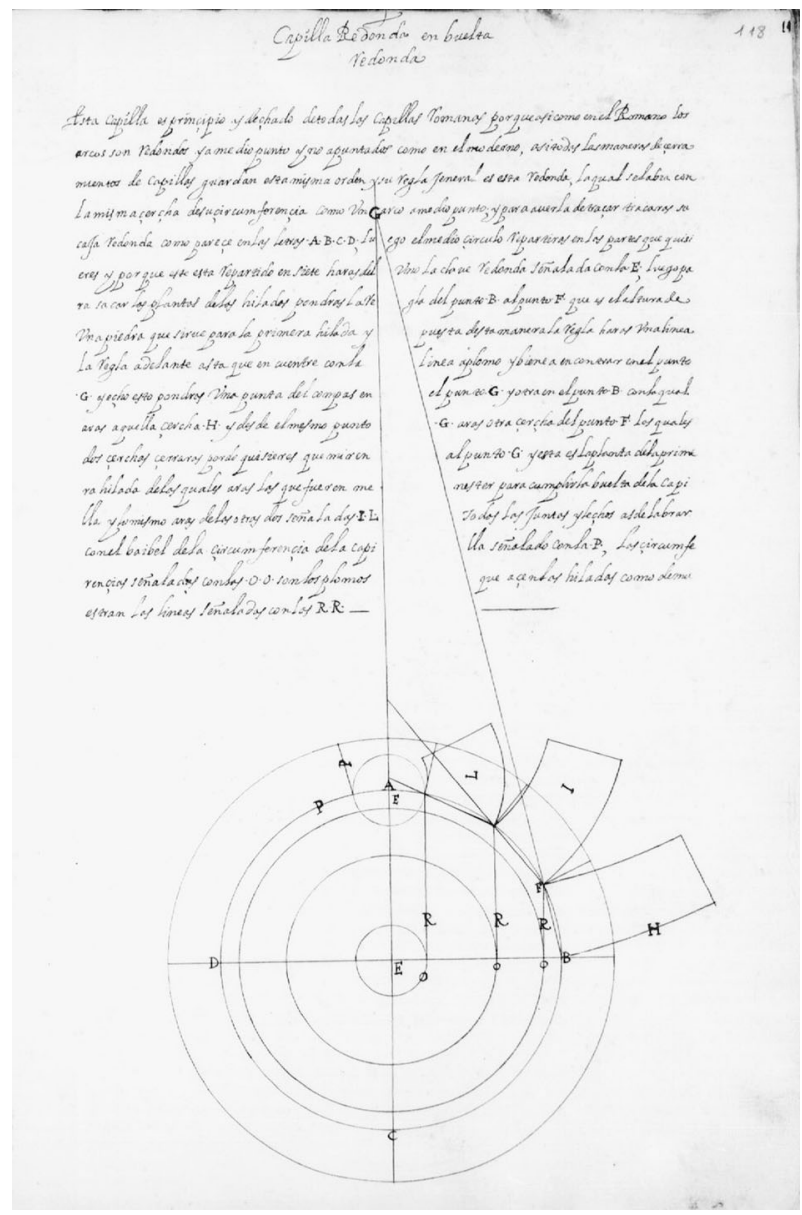

Fig. 8 The development of the sphere with conic projection in Vandelvira's treatise

geometrical definition of the templates of the nodes corresponding to two crossing arches. The principles of optimization achieved with these kinds of vaults are undeniably modern. The effectual geometric properties of the translation surfaces have been used to define the shell enclosing the MIST-Knowledge Centre for Masdar City (2010), where all primary structural beams are defined by an overall identical geometry (Fig. 15).

Toric surfaces offer similar advantages to those of transitional surfaces. There are several examples of the use of toric surfaces built around the turn of the millennium by Foster + Partners. The repetition of similar panels in the direction of rotation minimized the construction costs of these domes (Whitehead 2003). Vandelvira's treatise also describes this very particular vault (boveda de Murcia) and we can see a remarkable example in the sixteenth-century Junterón chapel inside Murcia Cathedral (Fig. 16). The first of the numerous examples built by Foster + Partners with this geometry was the vaulted roof of the Air Museum in Duxford (built in 


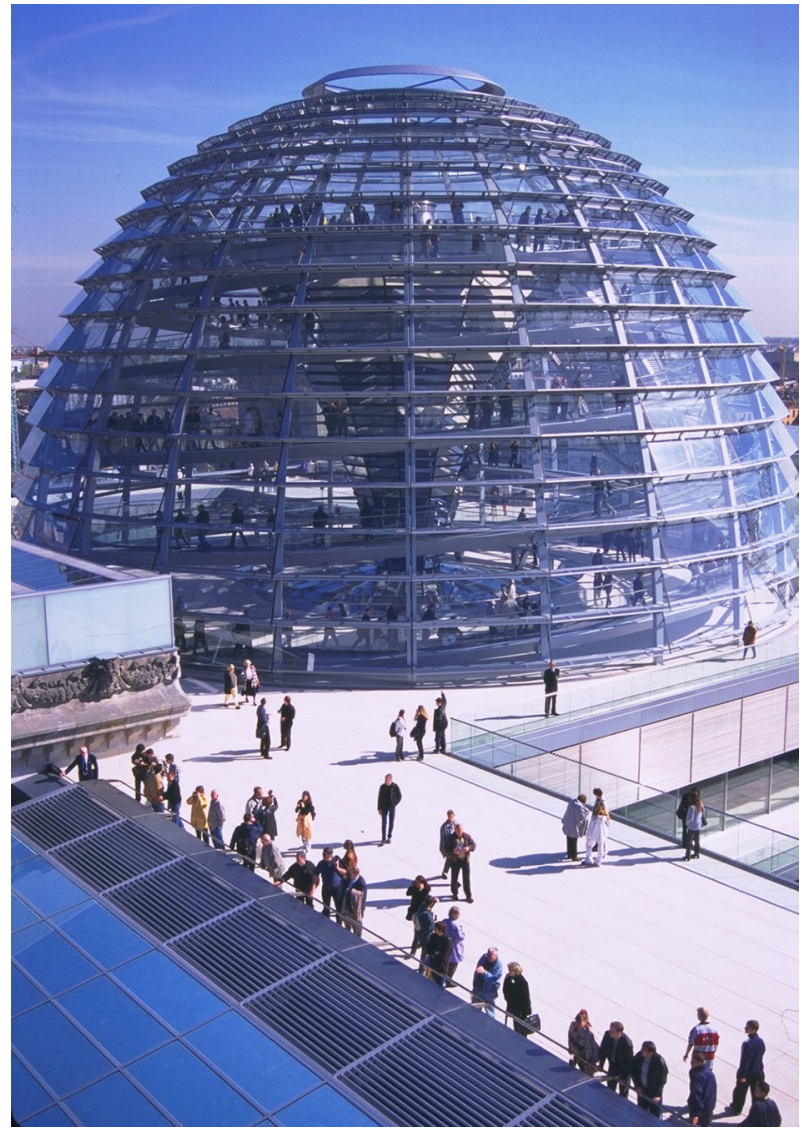

Fig. 9 The glass vault of the Reichstag divided in parallels. Courtesy of Foster + Partners

1997) (Fig. 17); defined geometrically as a portion of a torus (Fig. 18), it spans up to $90 \mathrm{~m}$ and is $18 \mathrm{~m}$ high, and is built with a double shell made with two $100 \mathrm{~mm}$ thick precast concrete units spaced $900 \mathrm{~mm}$ apart. The precast units of the lower shell, produced in a factory for reasons of economy and brought on site, have an inverted-T cross-section bearing the cast-in reinforcements of the connections. Once all the panels were put into place, the precast units were stitched together in situ with concrete to form continuous ribs to which real airplanes are currently hung as part of the museum's permanent exhibition. The geometry of the precast units started from the subdivision of the torus, which was defined by only two constant radii, in 924 panels made from only six sets of standard components. The structural and environmental performance required by the Duxford Museum roof led to the use of concrete, but conceptually we can observe the strong similarities with a classical stereotomic construction in which the materiality is mutated by using large precast concrete elements in lieu of stone blocks.

The use of precast components mixed with in situ concrete to form a vaulted structure is also celebrated in the Queen Alia International Airport in Amman. The 


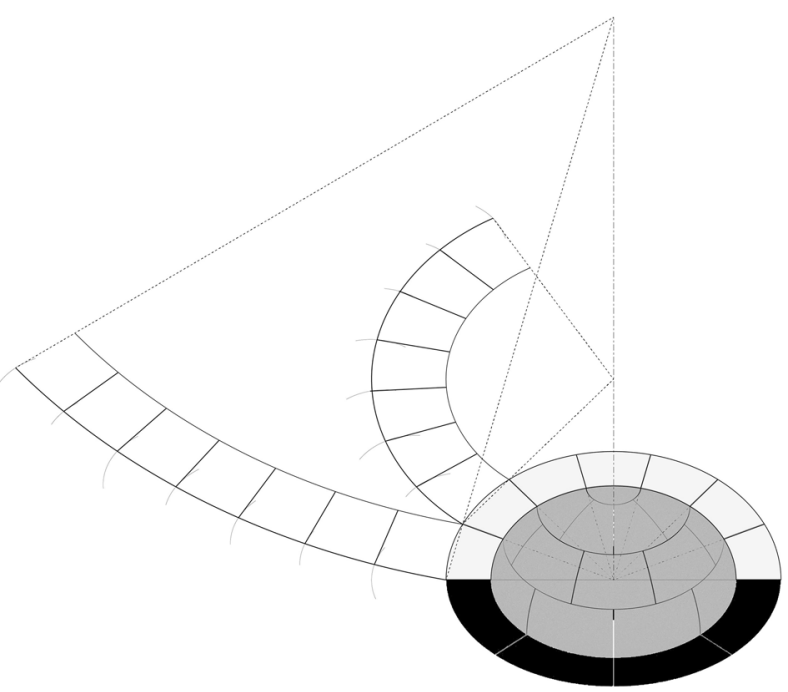

Fig. 10 Development of the sphere in parallels. Drawing of the author

tessellated roof canopy comprises a series of shallow concrete domes, resting on four arches which branch out from the supporting columns through split beams tonnes (Fig. 19). The columns, spaced $25 \mathrm{~m}$ from each other, were cast in situ, while the column heads, the arches and the roof shells were hollow precast elements which were later glued together by collocating additional reinforcement and an in situ concrete pour.

The precast column heads are of gigantic proportions: nearly $4 \mathrm{~m}$ wide, more than $7 \mathrm{~m}$ high, and weighing up to 20 , they were designed to let the split beams rest on them. The latter were precast in a Y shape to allow daylight to come in and they were configured to interlock with the pockets of the column heads. Once the beams were consolidated, their special profile of extrados was able to receive the eight portions in which the shell had been subdivided (Fig. 20). Due to its property of being extremely strong and yet able to produce a smooth finish, high-performance steel-fibre-reinforced concrete (HPC) was used to make the precast elements. Fascinatingly, we can observe how the construction system clearly subdivided and serialized the different components, defining an interlocking system which in principle is similar to joggled voussoirs. These pieces were shaped to favour the positioning of the precast elements and to make a seamless surface of intrados even if different component were assembled together.

The precast column heads were geometrically defined by a set of Boolean operations done in the design phase using a three-dimensional computer model (Fig. 21). This was also used to produce the moulds by slicing the same 3D model with several parallel planes, as often as every $2.5^{\circ}$ rotation, and successively communicating the contour lines to the fabricator.

We can see an analogy with the construction of the Gothic Tas-de-charge, namely the lower horizontal courses of ribs of a Gothic vault located just above the 


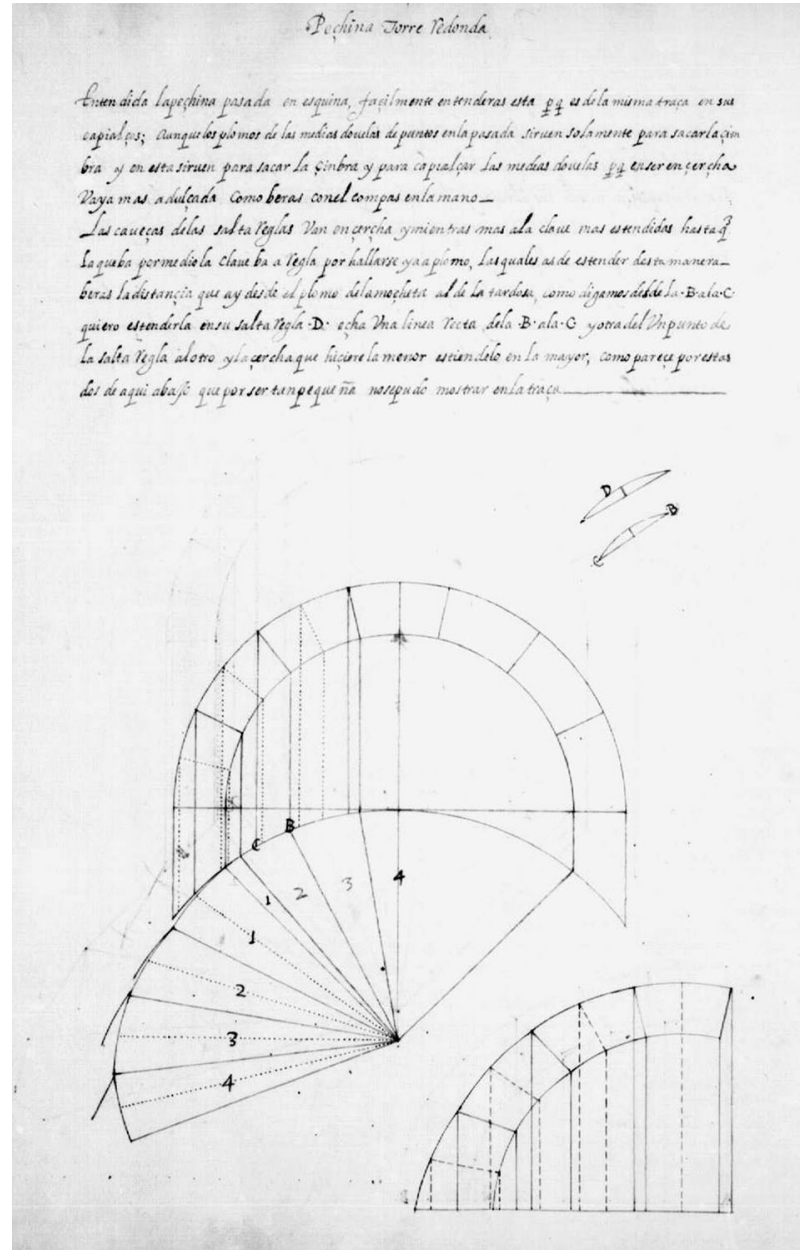

Fig. 11 Squinch vault in Vandelvira's treatise

spring line from which the arches depart. The stonemasons were producing several templates to represent the horizontal sections of the base of the arches, enabling precise control of the exact height and angle of departure of each rib.

The most emblematic materialization of the technology of lightweight precast concrete shells will be on show with the roof of the Kuwait International Airport, which is currently under construction (estimated completion is in 2020). Once completed, the colossal shells of the roof will be up to $35 \mathrm{~m}$ high and $45 \mathrm{~m}$ wide. The vaults placed along the perimeter of the building will be cantilevered $60 \mathrm{~m}$ with a system of back-span cables counterbalancing the force of gravity and keeping in compression the diaphragm arches hidden inside the shell (Figs. 22, 23). With this system, it will be possible to create an internal vaulted space which, at his maximum, will reach $100 \mathrm{~m}$ of clear span. The moulds for the precast panels will be obtained using flexible formwork to adapt to the free-form surface of the intrados of 

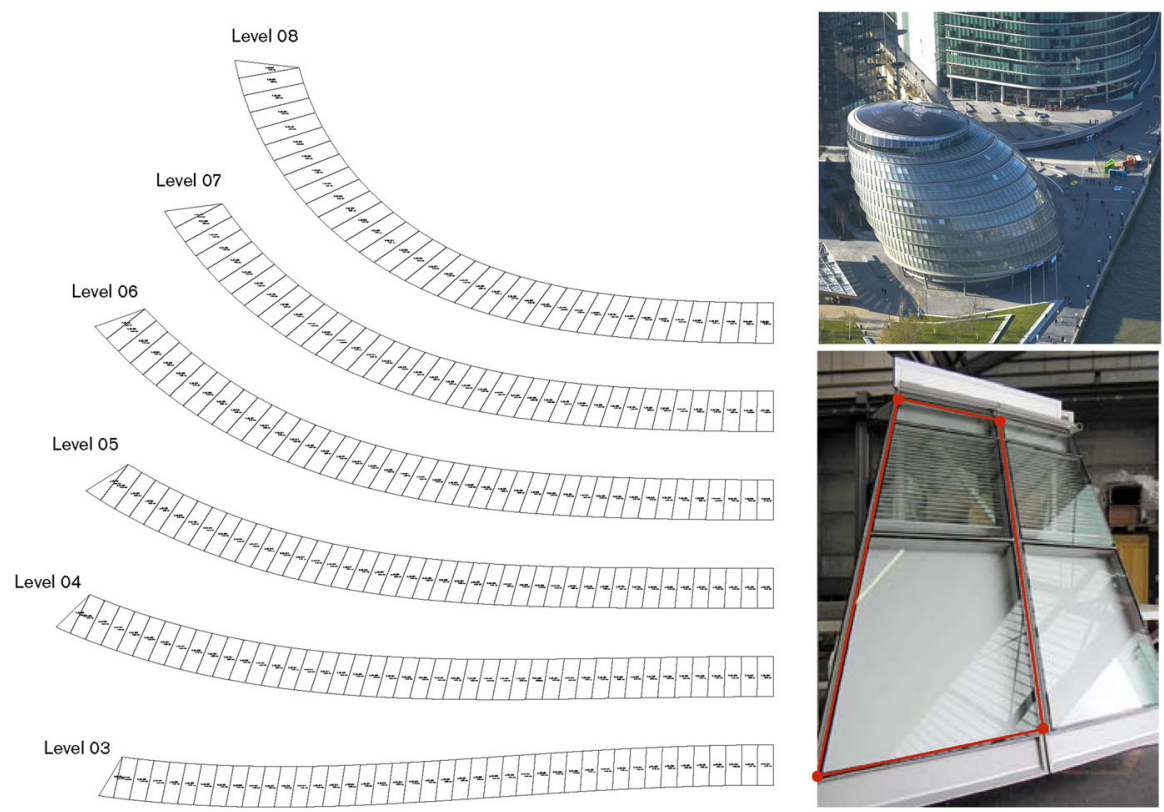

Fig. 12 Development of the glass panels of the London City Hall. Courtesy of Foster + Partners

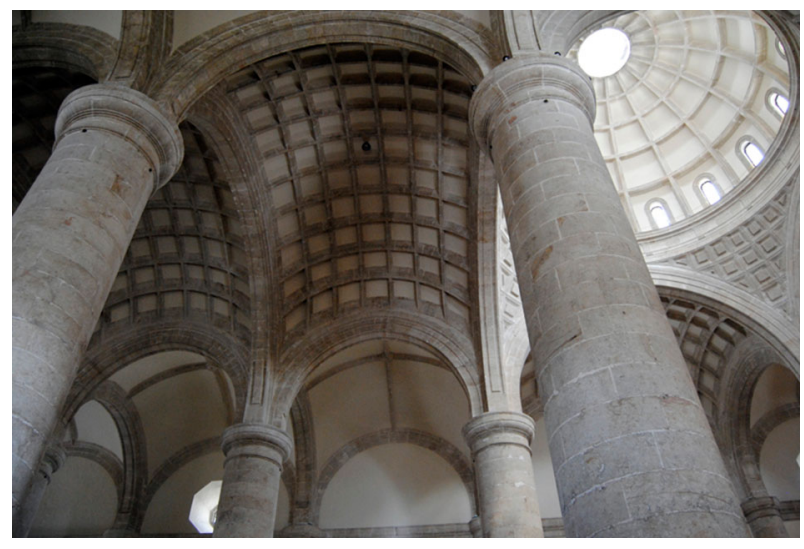

Fig. 13 Grid-crossing vaults of the San Ildefonso Cathedral, Mérida, Mexico

the vault. By replacing the stone material with components in high performance precast concrete, the structural capabilities and figurative language of the vaulted structures have enormously extended.

Depending on the context, however, the use of stone cannot be replaced. In order to give shape to the original design intent and to respect constructive constraints and site logistics, it has to be used together with other materials. The façade of the recently completed Blomberg Headquarters in London (2017) is articulated with horizontal and vertical stone fins (The Facade of Bloomberg's... 2017) which were 


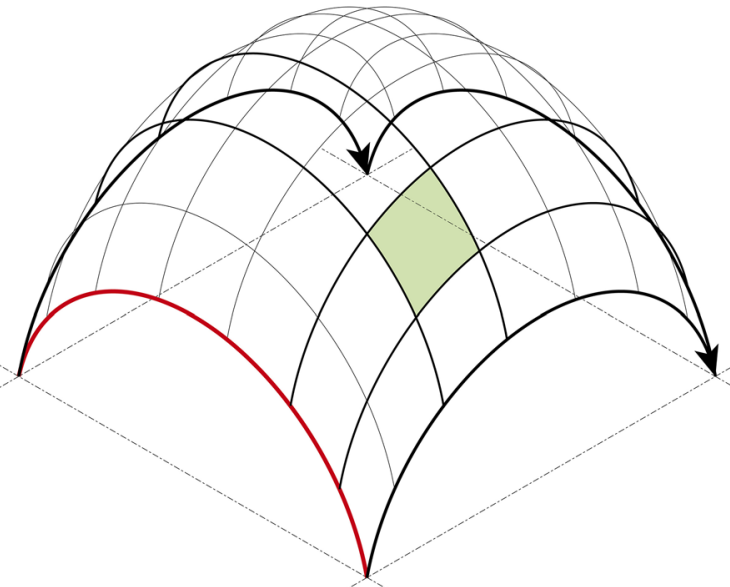

Fig. 14 Geometric definition of a grid-crossing vault with highlighted the flat panel that could be laid between the grids
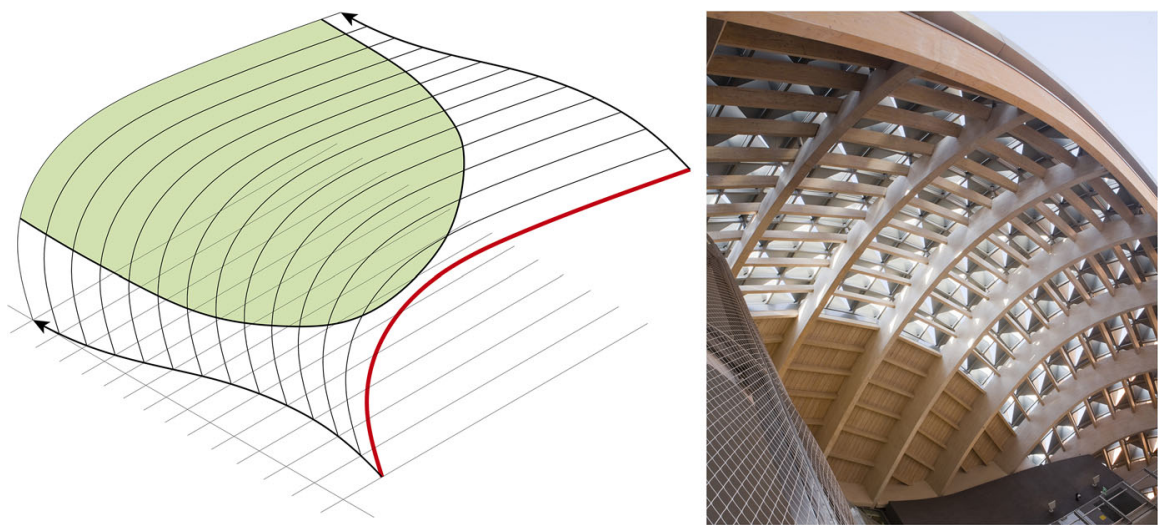

Fig. 15 The geometric definition of the structural beams of the MIST-Knowledge Centre and the underside of the roof. Photo courtesy of Nigel Young/Foster + Partners

fabricated as finished components offsite and assembled at a later stage when required by the construction programme. The stone was cut to size and attached to precast concrete units as a stay-in-place mould which span the length of a structural bay (more than $12 \mathrm{~m}$ ). The extremities of these fins were left uncovered from the stone to expose the fixing system in steel. Once the fins had been connected to the supporting structure, these nodes were covered by a special cross-shaped stone piece. The complex curved cut of the stone elements of the façade was done in Italy with a multi-axis wire saw, and each stone was hand finished by highly skilled masons (It Starts With a Hole in the Ground... 2017).

On other occasions, the finished surface produced on the stone by the CNC machine is considered appropriate for the aesthetic intent of the project, as happened 

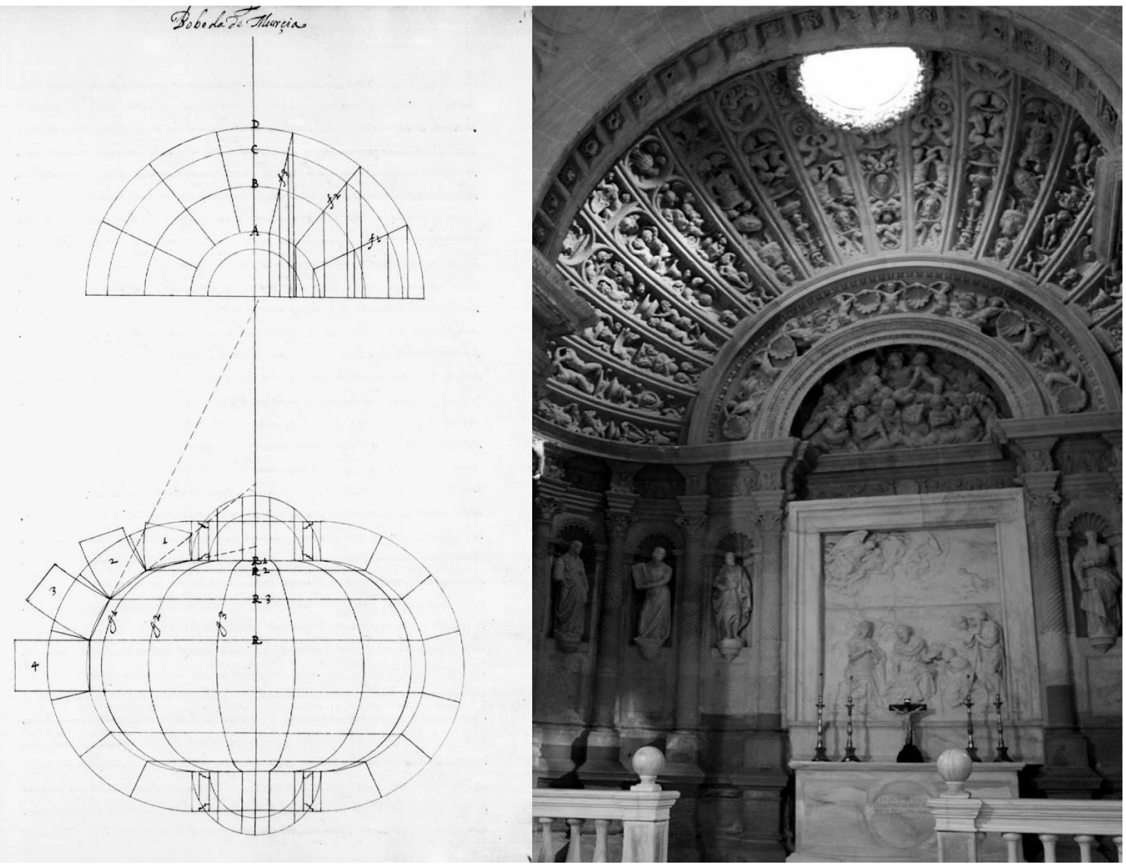

Fig. 16 Junteron chapel in Murcia Cathedral and Vandelvira's drawing from his treatise on stereotomy

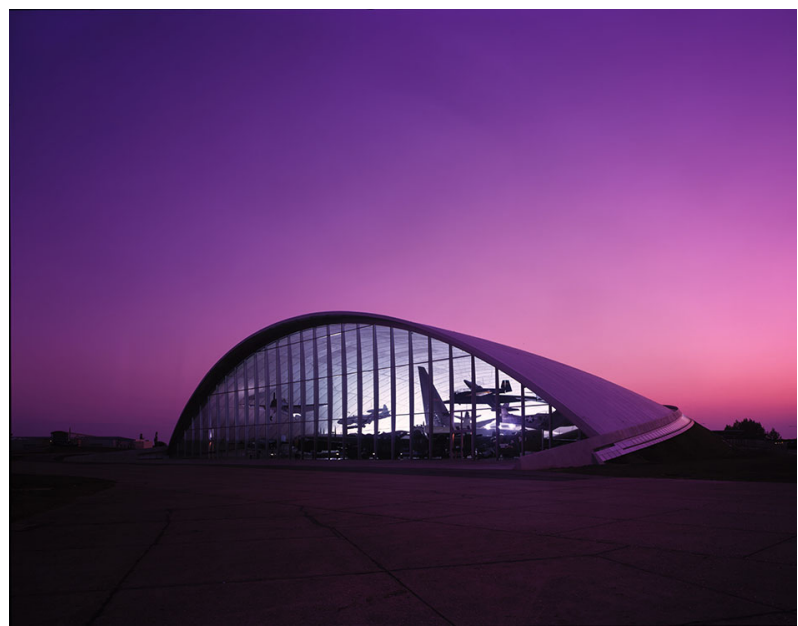

Fig. 17 Air Museum in Duxford. Courtesy of Nigel Young/Foster + Partners

in one of the early options for the stone podium in the Oceanwide Center, a project currently under construction. The panels were defined by a ruled geometry and were nested within a volumetric block of stone. Its geometry and the cut with a diamond wire mounted on a robotic arm helped to reduce stone wastage (Fig. 24). 


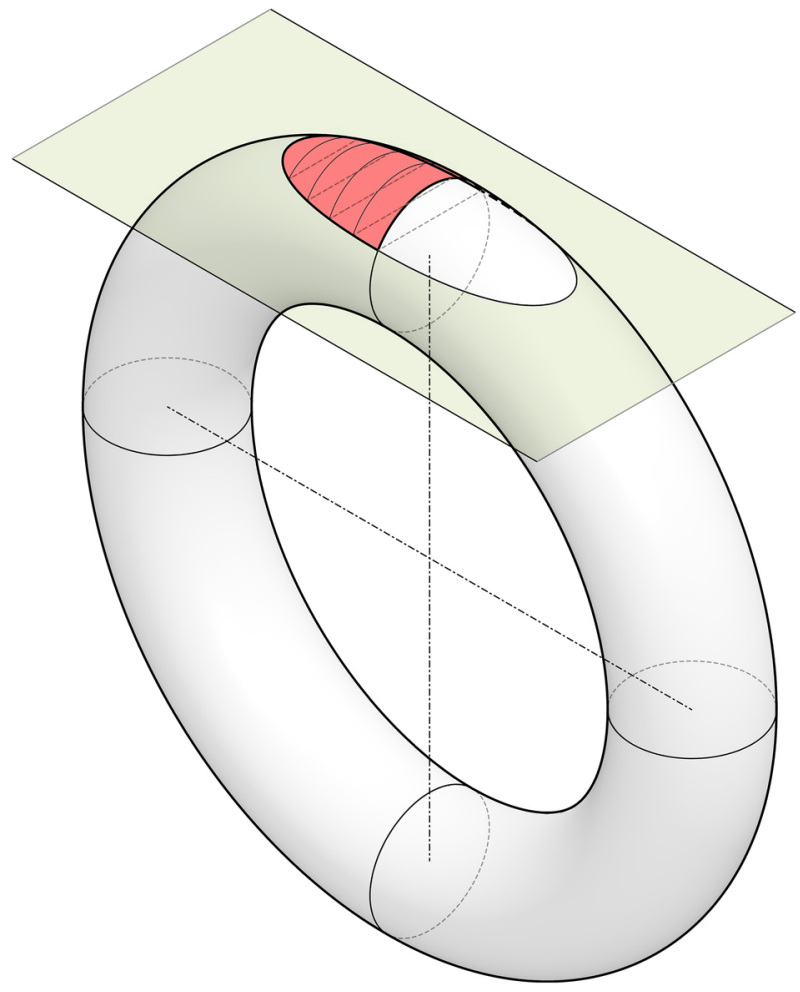

Fig. 18 The portion of torus to define the shell of the Air Museum in Duxford

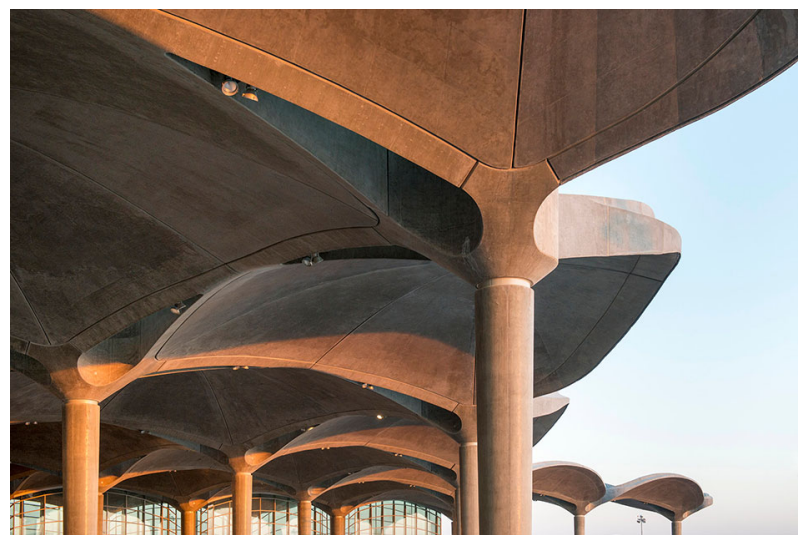

Fig. 19 The roof of Queen Alia International Airport 


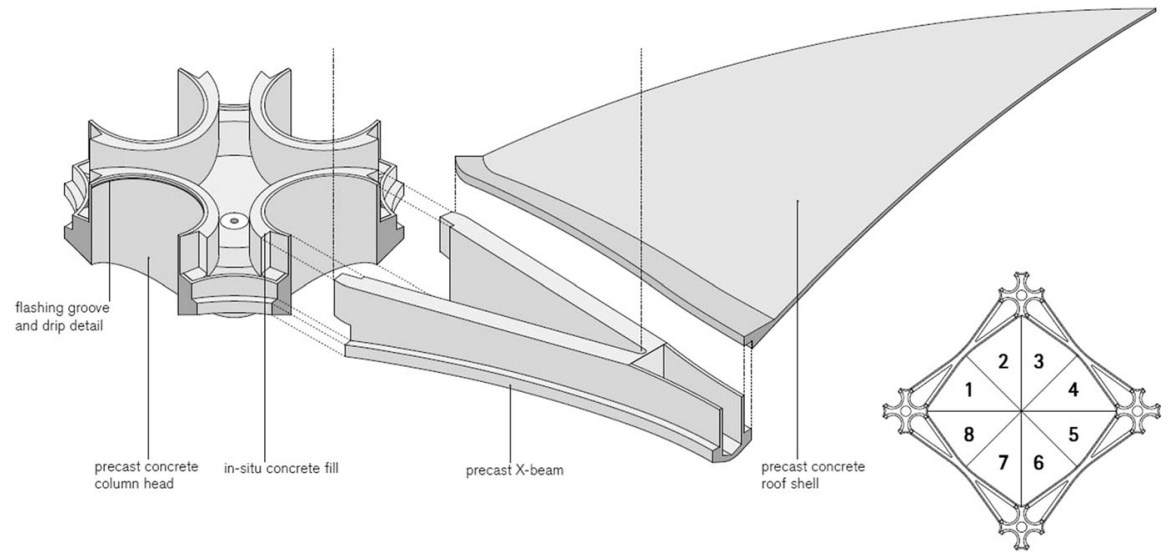

Fig. 20 The structural node showing the interlocking components

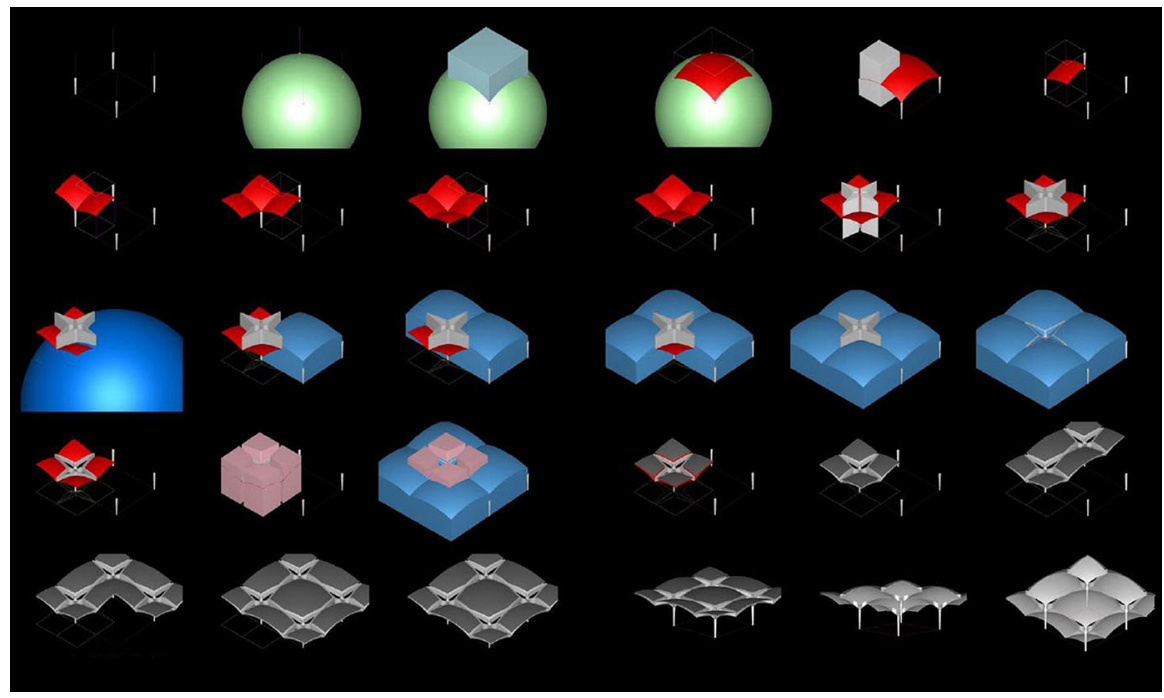

Fig. 21 Boolean operations required to define the geometry of the vaulted system

\section{Conclusions}

The discipline of stereotomy has been revived in the past few decades in a new wave of academic historical research and experimental projects explicitly dedicated to it; these have led to a renewed interest in its application in today's architecture. The growing corpus of built examples and publications focused on this topic confirm this trend.

However, in certain areas of architectural design dealing with highly technological buildings, the principles defining classical stereotomy have been widely applied and are not new findings in today's architecture. It might be said that the principles 


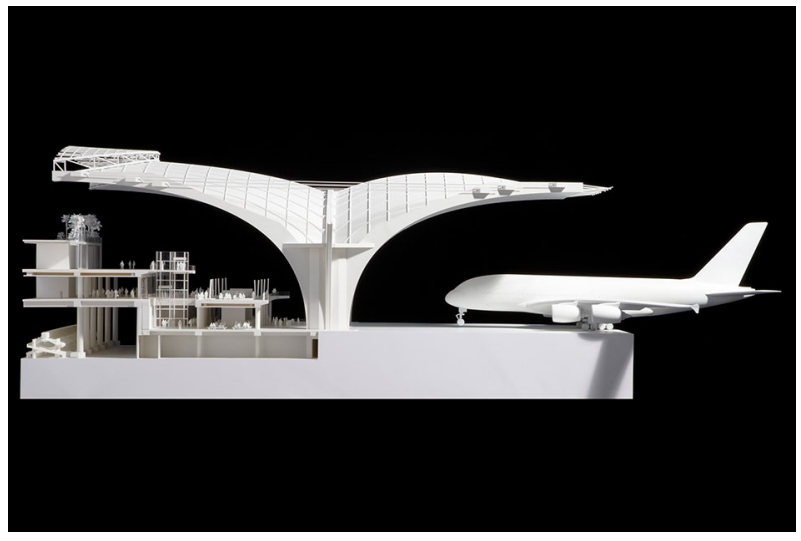

Fig. 22 Cross-section model of the roof

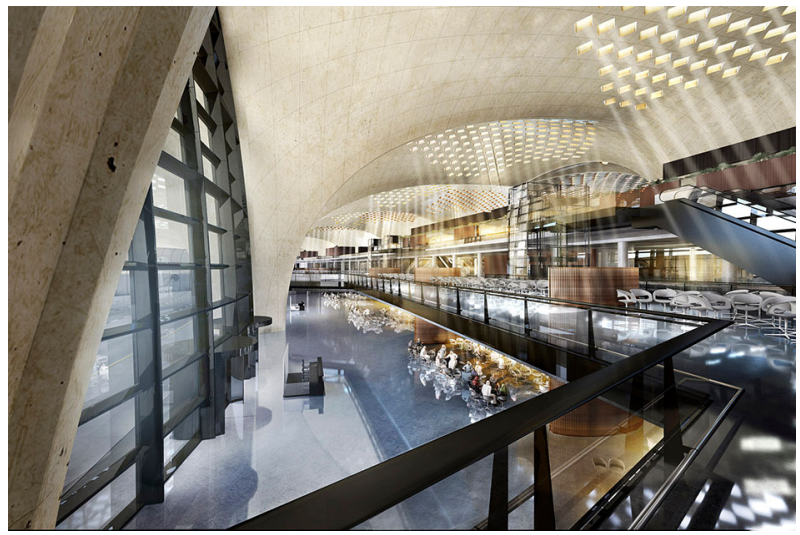

Fig. 23 Visualization of the interior space

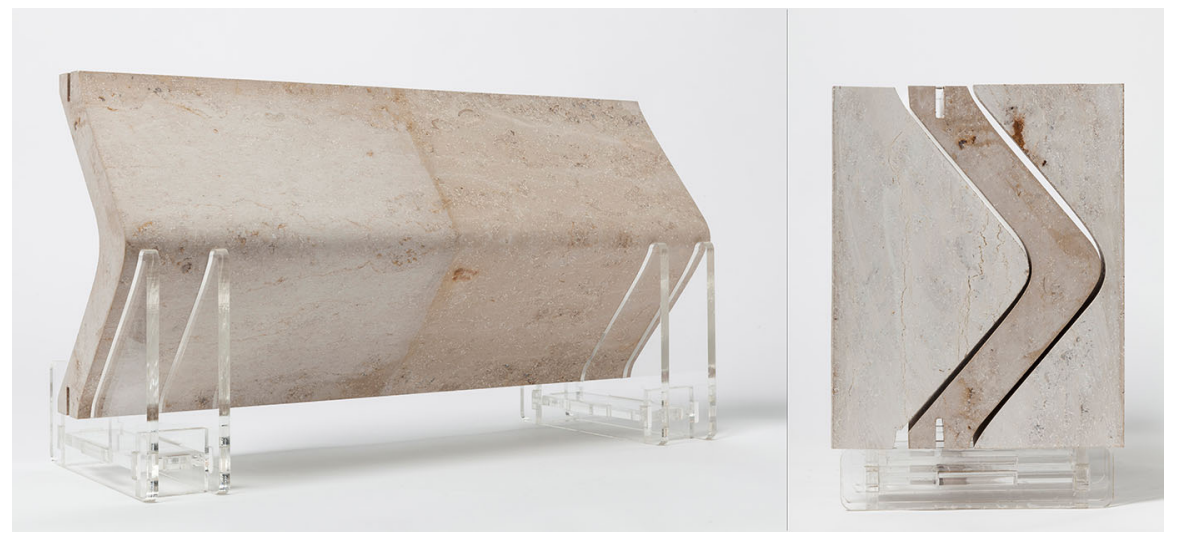

Fig. 24 The cut panel and the original stone block containing it 
have been continuously "rediscovered" and adapted to the everchanging market and the technology-driven architectural design.

Several projects designed by Foster + Partners have been characterized by a thorough geometrical and constructive optimization which, as seen with the analogies reproduced in this article, can be closely related to the teachings of the classical art of stereotomy.

The Renaissance explored the several variations of subdividing regular curved surfaces as spheres and cones, and controlling and building with great approximation double-curved surfaces and interlocking systems in stone.

Thanks to the use of new materials or the different combinations of new and traditional materials, and the opportunity afforded by the actualization of the design and production tools, it is possible to produce innovative and unseen designs based on the stereotomic principles flagged up earlier in this article.

Nevertheless, in the vast ocean of choices which technology offer today, the direction where this is heading is not yet clear: advanced robotics and additive manufacturing, although developing, haven't given clear indications as to where this is going and their pragmatic application in large scale construction. These scenarios are opening studies in new fields and opening new directions for stereotomy.

The full potential, for now, is still to explore.

\section{References}

De L'Orme, P. 1567. Le premier tome de l'architecture. Paris, chez Federic Morel, rue S. Jean de Beauvais. 1567.

Fallacara, G. 2006. Digital Stereotomy and Topological Transformations. In: Proceedings of the Second International Congress on Construction History, vol. 1, 1075-1092. Cambridge University.

Fallacara, G. 2012. For a History of Modern Stereotomy: 1951-2011. In: Stereotomy. Stone Architecture and New Research. Paris: Press des Ponts.

Fallacara, G. 2013. Stereotomy: Stone Architecture and New Research. Paris: Press des Ponts

Fallacara, G. and Barberio, M. 2016. Stone skin - Hyper-light double-layered granite skin with fiber reinforcement. In: Proceedings of the 11th Conference on Advanced Building Skins. Berna: Advanced Building Skins GmbH.

Frankl, P. 1963. Gothic Architecture. Baltimore: Penguin Books.

Leroy, C. 1877. Traité de stéréotomie: comprenant les applications de la géométrie descriptive à la théorie des ombres, la perspective linéaire, la gnomonique, la coupe des pierres et la charpente. Paris: Gauthier-Villars

Palacios, J.C. 2003. Trazas y Cortes de Cantería en el Renacimiento Español. Madrid: Munilla-Lería.

Palacios, J.C. 2009. La cantería medieval: La construcción de la bóveda gótica española. Madrid: Munilla-Leria

Pérouse de Montclos, J.M. 1982. L’Architecture à la française, du milieu du XVe à la fin du XVIIIe siècle. Paris: Picard.

Peters, B. 2008. Copenhagen Elephant House: A Case Study of Digital Design Processes. In: Silicon + Skin: Biological Processes and Computation, Proceedings of the 28th Annual Conference of the Association for Computer Aided Design in Architecture (ACADIA). Minneapolis.

Rabagliati, J., C. Huber and D. Linke. 2017. Balancing Complexity and Simplicity. In: Fabricate 2014. Negotiating Design \& Making. eds. F. Gramazio, M. Kohler and S. Langenberg, 44-51. London: UCL Press.

Rippmann, M. and Block, P. 2013. Rethinking structural masonry: unreinforced, stone-cut shells. In: Proceedings of the Institution of Civil Engineers - Construction Materials 2013, 378-389. 
Rovira i Rabassa, A. 1897. Estereotomía de la piedra. Barcelona: Librería y estampería artística.

Rovira i Rabassa, A. 1900a. La madera y su estereotomía. Barcelona: Librería de Álvaro Verdaguer.

Rovira i Rabassa, A. 1900b. El hierro sus cortes y enlaces. Barcelona: Librería de Ribó y Marín.

Tellia, F. and Palacios, J.C. 2015. Las bóvedas de crucería del manuscrito Llibre de trasas de viax y muntea, de Joseph Ribes. In: Locus amoenus, 13. Barcelona: Servei de Publicacions.

Trevisan, C. 2000. Sulla stereotomia, il CAD e le varie trompe d'Anet. In: Il disegno e la pietra. ed. R. Migliari, 27-53. Roma: Gangemi.

Vandelvira, A. de, 1578-1589. Libro de trazas de cortes de piedras. Madrid: Biblioteca de la Escuela de Arquitectura, ms R 10.

Whitehead, H. 2003. Laws of Form in Architecture in the Digital Age: Design and Manufacturing. ed. Branko Kolarevic. London and New York: Spon Press.

\section{Websites}

www.fosterandpartners.com. Last accessed: October 2017.

It Starts With a Hole in the Ground - Bloomberg's New European Headquarters. https://www.youtube. com/watch?v=VwfdKbzwqe4. YouTube. Last accessed: October 2017.

The Facade of Bloomberg's London Building: It's All in the Details. https://www.youtube.com/watch?v= HvJjHuzAgg0. YouTube. Last accessed: October 2017.

Fabio Tellia is currently an Associate at Foster + Partners, London, where he is a member of one of the firm's project teams. He is also a Ph.D. candidate at the Universidad Politécnica de Madrid, writing his thesis on Joseph Ribes' manuscript on stereotomy. He has lectured in various academic institutions in Spain and the UK. His research focuses on the geometric and constructive analysis of ribbed vaults and the study of stone stereotomy, with an emphasis on its diffusion in Catalonia. 